\title{
Salicylic acid alleviates decreases in photosynthesis under heat stress and accelerates recovery in grapevine leaves
}

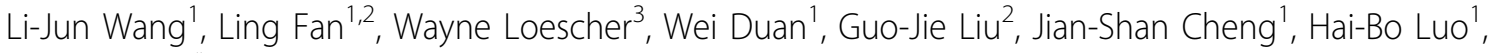
Shao-Hua $\mathrm{Li}^{4^{*}}$

\begin{abstract}
Background: Although the effect of salicylic acid (SA) on photosynthesis of plants including grapevines has been investigated, very little is yet known about the effects of SA on carbon assimilation and several components of PSII electron transport (donor side, reaction center and acceptor side). In this study, the impact of SA pretreatment on photosynthesis was evaluated in the leaves of young grapevines before heat stress $\left(25^{\circ} \mathrm{C}\right)$, during heat stress $\left(43^{\circ} \mathrm{C}\right.$ for $5 \mathrm{~h}$ ), and through the following recovery period $\left(25^{\circ} \mathrm{C}\right)$. Photosynthetic measures included gas exchange parameters, PSII electron transport, energy dissipation, and Rubisco activation state. The levels of heat shock proteins (HSPs) in the chloroplast were also investigated.

Results: SA did not significantly $(P<0.05)$ influence the net photosynthesis rate $\left(P_{\mathrm{n}}\right)$ of leaves before heat stress. But, SA did alleviate declines in $P_{\mathrm{n}}$ and Rubisco activition state, and did not alter negative changes in PSII parameters (donor side, acceptor side and reaction center $\mathrm{Q}_{A}$ ) under heat stress. Following heat treatment, the recovery of $P_{n}$ in SA-treated leaves was accelerated compared with the control $\left(\mathrm{H}_{2} \mathrm{O}\right.$-treated) leaves, and, donor and acceptor parameters of PSII in SA-treated leaves recovered to normal levels more rapidly than in the controls. Rubisco, however, was not significantly $(P<0.05)$ influenced by SA. Before heat stress, SA did not affect level of HSP 21, but the HSP21 immune signal increased in both SA-treated and control leaves during heat stress. During the recovery period, HSP21 levels remained high through the end of the experiment in the SA-treated leaves, but decreased in controls.
\end{abstract}

Conclusion: SA pretreatment alleviated the heat stress induced decrease in $P_{\mathrm{n}}$ mainly through maintaining higher Rubisco activition state, and it accelerated the recovery of $P_{\mathrm{n}}$ mainly through effects on PSII function. These effects of SA may be related in part to enhanced levels of HSP21.

\section{Background}

Heat stress due to high ambient temperatures is a serious threat to crop production [1]. Photosynthesis is one of the most sensitive physiological processes to heat stress in green plants [2]. Photochemical reactions in thylakoid lamellae in the chloroplast stroma have been suggested as the primary sites of injury at high temperature [3]. Heat stress may lead to the dissociation of the oxygen evolving complex (OEC), resulting in an imbalance during the electron flow from OEC toward the

\footnotetext{
* Correspondence: shhli@wbcas.cn

${ }^{4}$ Key Laboratory of Pant Germplasm Enhancement and Speciality Agriculture, Wuhan Botanical Garden, Chinese Academy of Sciences, Wuhan 430074, PR
} China

(c) 2010 Wang et al; licensee BioMed Central Ltd. This is an Open Access article distributed under the terms of the Creative Commons Attribution License (http://creativecommons.org/licenses/by/2.0), which permits unrestricted use, distribution, and reproduction in any medium, provided the original work is properly cited. acceptor side of photosystem II (PSII) [4]. Heat stress may also impair other parts of the reaction center, e.g., the D1 and/or the D2 proteins [5]. Several studies have suggested that heat stress inhibits electron transport at the acceptor side of PSII [6-8]. Direct measurements of the redox potential of $\mathrm{Q}_{\mathrm{A}}$ have demonstrated that heat stress induces an increase in the midpoint redox potential of the $\mathrm{Q}_{\mathrm{A}} / \mathrm{Q}_{\mathrm{A}}{ }^{-}$couple in which electron transfer from $\mathrm{Q}_{\mathrm{A}}{ }^{-}$to the secondary quinone electron acceptor of PSII $\left(\mathrm{Q}_{\mathrm{B}}\right)$ is inhibited [6-8]. On the other hand, some studies have shown that the decreased photosynthesis could be attributed to the perturbations of biochemical processes, such as decreases in ribulose bisphosphate carboxylase/oxygenase (Rubisco) activity and decreases 
in ribulose-1,5-bisphosphate (RuBP) or Pi regeneration capacity [9].

Plants have evolved a series of mechanisms to protect the photosynthetic apparatus against damage resulting from heat stress. For example, many studies have shown that heat dissipation of excess excitation energy is an important mechanism $[10,11]$. When plants are subjected to heat stress, a small heat shock protein is expressed that binds to thylakoid membranes and protects PSII and whole-chain electron transport [12]. But, when plants are subjected to more severe stress, these protective mechanisms may be inadequate. However, some growth regulators have been used to induce or enhance these protective functions [13,14].

Salicylic acid (SA) is a common plant-produced phenolic compound that can function as a plant growth regulator. Various physiological and biochemical functions of SA in plants have been reported [15], and SA has received much attention due to its role in plant responses to abiotic stresses, including heat stress. SA application may improve photosynthetic capacity in spring wheat and barley under salt stress and drought stress $[16,17]$ and Phillyrea angustifolia and wheat seedlings under drought stress $[18,19]$. But, relatively little is yet known about SA-related mechanisms that alleviate the decline of photosynthesis in these studies. In addition, exogenous application of SA or acetylsalicylate has been shown to enhance thermotolerance in tobacco and Arabidopsis [20-24]. Wang and $\mathrm{Li}$ [25] reported that spraying with a $0.1 \mathrm{mM}$ solution of SA decreased thiobarbituric acidreactive substances and relative electrolyte leakage in young grape leaves under heat stress, indicating that SA can induce intrinsic heat tolerance in grapevines. Dat et al. [20] showed that thermotolerance (expressed as survival rate after heat treatment) of mustard (Sinapis alba L.) seedlings could be obtained by SA treatment. Lopez-Delgado et al. [22] reported that thermotolerance (expressed as survival rate after heat treatment) can be induced in potato microplant tissues by treatment with acetylsalicylic acid, and Wang et al. [26] reported that SA treatment can maintain at higher $P_{\mathrm{n}}$ in grape leaves under heat stress. There are, however, very few reports on how SA affects the photochemical aspects of PSII in plants under heat stress, such as energy absorption, utilization, and dissipation of excess energy.

Worldwide, grape has become one of the most productive and important specialty crops. In many production regions, the maximum midday air temperature can reach more than $40^{\circ} \mathrm{C}$, which is especially critical at veraison when the berries are rapidly accumulating photosynthates. Climate change may produce more frequent high temperature conditions close to the current northern limit of grape cultivation [27-29]. Extreme temperatures may endanger berry quality and economic returns
[30]. Wang and Li [25] have previously reported that SA alleviates heat damage of plants by up-regulating the antioxidant system. Here, in the present experiment, we investigated the effect of SA on photosynthesis of grape leaves before, during and after heat stress.

\section{Results}

Net photosynthesis rate $\left(P_{n}\right)$, substomatal $\mathrm{CO}_{2}$ concentration $\left(C_{\mathrm{i}}\right)$ and stomatal conductance $\left(g_{\mathrm{s}}\right)$

At normal growth temperature, spraying SA did not induce significant $(P<0.05)$ changes in $P_{\mathrm{n}}, C_{\mathrm{i}}$ and $g_{\mathrm{s}}$ in the grapevines (Fig. 1). When these plants were heat stressed at $43^{\circ} \mathrm{C}$ for $5 \mathrm{~h}, P_{\mathrm{n}}$ and $g_{\mathrm{s}}$ sharply declined while $C_{\mathrm{i}}$ abruptly rose; however, the SA-treated plants had significantly higher $P_{n}$ values than the controls $\left(\mathrm{H}_{2} \mathrm{O}+\right.$ HT). There was no significant difference in $C_{\mathrm{i}}$ between SA-treated and control plants in normal growth conditions. During recovery, $P_{\mathrm{n}}$ and $g_{\mathrm{s}}$ of heat treated plants increased and $C_{\mathrm{i}}$ steeply decreased (on Day 3 ). $P_{\mathrm{n}}, C_{\mathrm{i}}$ and $g_{\mathrm{s}}$ of these plants then gradually increased, and the SA-treated plants had higher $P_{\mathrm{n}}$ than the control plants. However, no significant differences were found in $P_{\mathrm{n}}, C_{\mathrm{i}}$ and $g_{\mathrm{s}}$ between SA and control plants on Day 6 (Fig. 1).

\section{Donor side, reaction centre and acceptor side of PSII}

In general, a typical polyphasic rise of fluorescence transients determined by a Handy Plant Efficiency Analyzer (Hanstech, UK) includes phases O, J, I and P. It has been shown that heat stress can induce a rapid rise in these polyphasic fluorescence transients. This rapid rise, occurring at around $300 \mu \mathrm{s}$, has been labeled as $\mathrm{K}$, and is the fastest phase observed in the OJIP transient which, consequently, becomes an OKJIP transient [31]. It has also been shown that phase $\mathrm{K}$ is caused by an inhibition of electron transfer to the secondary electron donor of PSII, $\mathrm{Yz}$, which is due to a damaged oxygen evolving complex (OEC). The amplitude of step $\mathrm{K}$ can therefore be used as a specific indicator of damage to the OEC [32]. Fig. 2 shows the changes in amplitude in the K step expressed as the ratio $\mathrm{W}_{\mathrm{K}}$. SA spraying did not result in obvious changes of $W_{K}$ in grape leaves under normal temperature. When control and SA-sprayed plants were stressed by heat, $\mathrm{W}_{\mathrm{K}}$ of both went up quickly, and similarly. During recovery $\mathrm{W}_{\mathrm{K}}$ of the $\mathrm{SA}$ treatment dropped more quickly than $\mathrm{W}_{\mathrm{K}}$ of the control. Moreover, $\mathrm{W}_{\mathrm{K}}$ of the SA treatment was significantly lower than that of the control on the first day of recovery (Day 3).

The density of $\mathrm{RC}_{\mathrm{QA}}$ in the control and SA-treated leaves was unchanged at normal temperature. When heat stress was imposed, density of $\mathrm{RC}_{\mathrm{QA}}$ declined rapidly. During the recovery period, density of $\mathrm{RC}_{\mathrm{QA}}$ of SA-sprayed leaves rose and nearly reached normal levels on Day 3, but the control $\mathrm{RC}_{\mathrm{QA}}$ recovered slowly, and reached normal levels on Day 5 (Fig.2). 


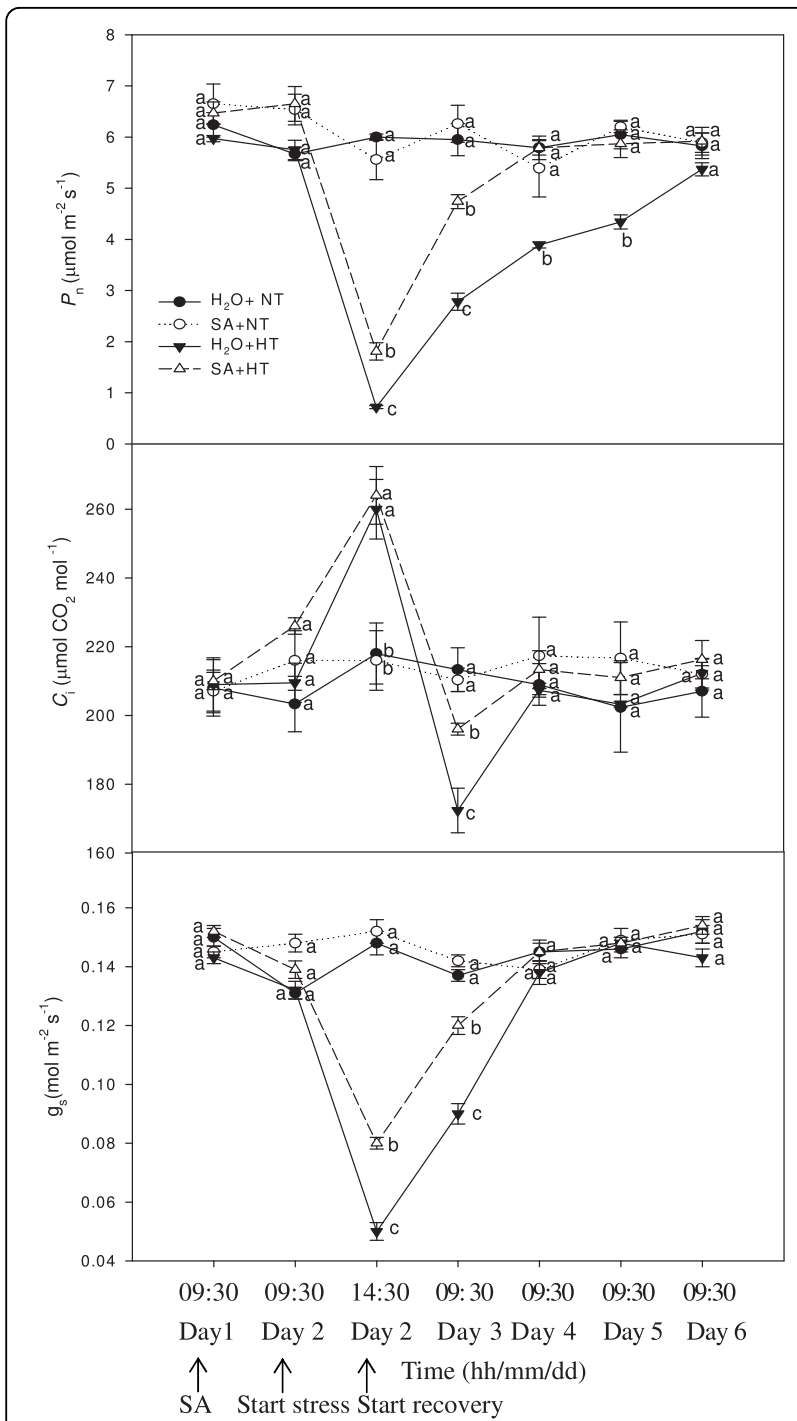

Figure $1 P_{n}, C_{\mathrm{i}}$ and $g_{\mathrm{s}}$ in leaves of grape plants sprayed with $\mathrm{H}_{2} \mathrm{O}$ (filled circles) and $\mathrm{SA}$ (open circles) at normal growth temperature $\left(\mathrm{NT}, 25^{\circ} \mathrm{C}\right.$ ), and treated with $\mathrm{H}_{2} \mathrm{O}$ (filled triangles) and SA (open triangles) under heat stress $\left(\mathrm{HT}, 43^{\circ} \mathrm{C}\right)$ and recovery. Each value is the mean \pm SE of 4 replicates. $0.1 \mathrm{mM} \mathrm{SA}$ solution or $\mathrm{H}_{2} \mathrm{O}$ was sprayed at 9:30 h on Day 1, immediately afterwards photosynthesis and chlorophyll fluorescence parameters were measured. Heat stress was from 9:30 to 14:30 h on Day 2. The recovery period was from 14:30 h on Day 2 to 9:30 h on Day 6. At the same time point, numerical values with different letters are significantly different $(P<0.05)$.

Fig. 3 demonstrates (1) the changes in maximum quantum yield for primary photochemistry $\left(\varphi_{\mathrm{Po}}\right),(2)$ the efficiency with which a trapped excitation can move an electron into the electron transport chain further than $\mathrm{Q}_{\mathrm{A}}{ }^{-}\left(\psi_{\mathrm{Eo}}\right)$, and (3) the quantum yield of electron transport $\left(\varphi_{\mathrm{Eo}}\right)$ in grape leaves. Under normal temperatures, spraying SA did not change $\varphi_{\mathrm{Po}}, \psi_{\mathrm{Eo}}$ and $\varphi_{\mathrm{Eo}}$. With heat stress, $\varphi_{\mathrm{Po}}, \psi_{\text {Eo }}$ and $\varphi_{\text {Eo }}$ in both SA-treatedand control

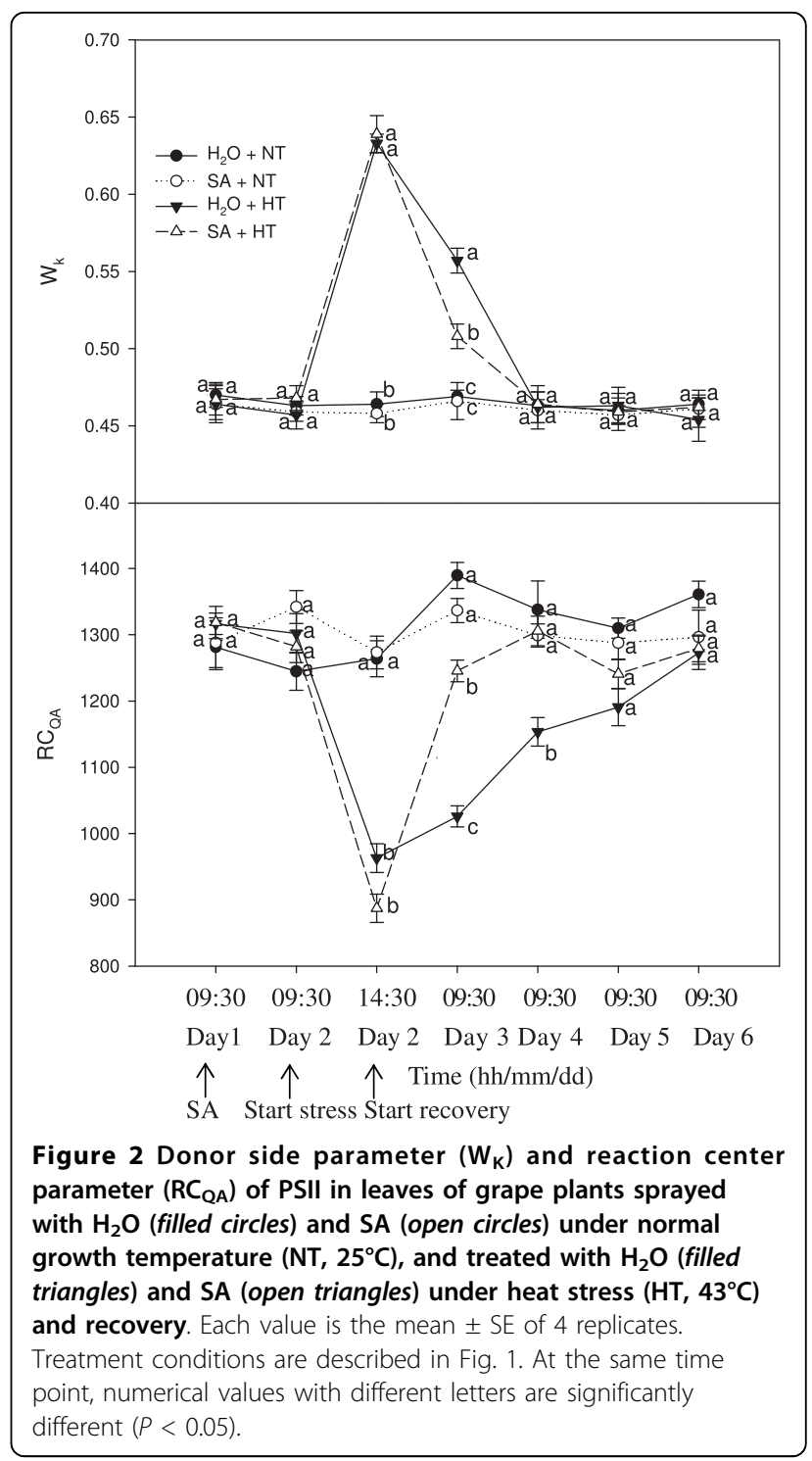

leaves significantly declined. During recovery, $\varphi_{\mathrm{Po}}, \psi_{\mathrm{Eo}}$ and $\varphi_{\mathrm{Eo}}$ of SA-treated leaves rapidly increased, and these parameters were markedly greater in SA-treated leaves than in the controls on Day 3.

Fig. 4 demonstrates the changes in approximated initial slope of the fluorescence transient $\left(M_{\mathrm{o}}\right)$ and in the redox state of PSI expressed as $\left(1-V_{\mathrm{i}}\right) /\left(1-V_{\mathrm{j}}\right)$. At normal temperature, spraying SA did not change $M_{\mathrm{o}}$ and $\left(1-V_{\mathrm{i}}\right) /\left(1-V_{\mathrm{j}}\right)$. After heat stress, $M_{\mathrm{o}}$ and $\left(1-V_{\mathrm{i}}\right) /\left(1-V_{\mathrm{j}}\right)$ rose rapidly. During recovery, $M_{\mathrm{o}}$ and $\left(1-V_{\mathrm{i}}\right) /\left(1-V_{\mathrm{j}}\right)$ of SAtreated leaves rapidly declined, and these parameters were markedly less in SA-treated leaves than in the control leaves on the first day of recovery (Day 3).

\section{PSIl efficiency and excitation energy dissipation}

PSII efficiency and excitation energy dissipation in grape leaves was examined by modulated fluorescence 


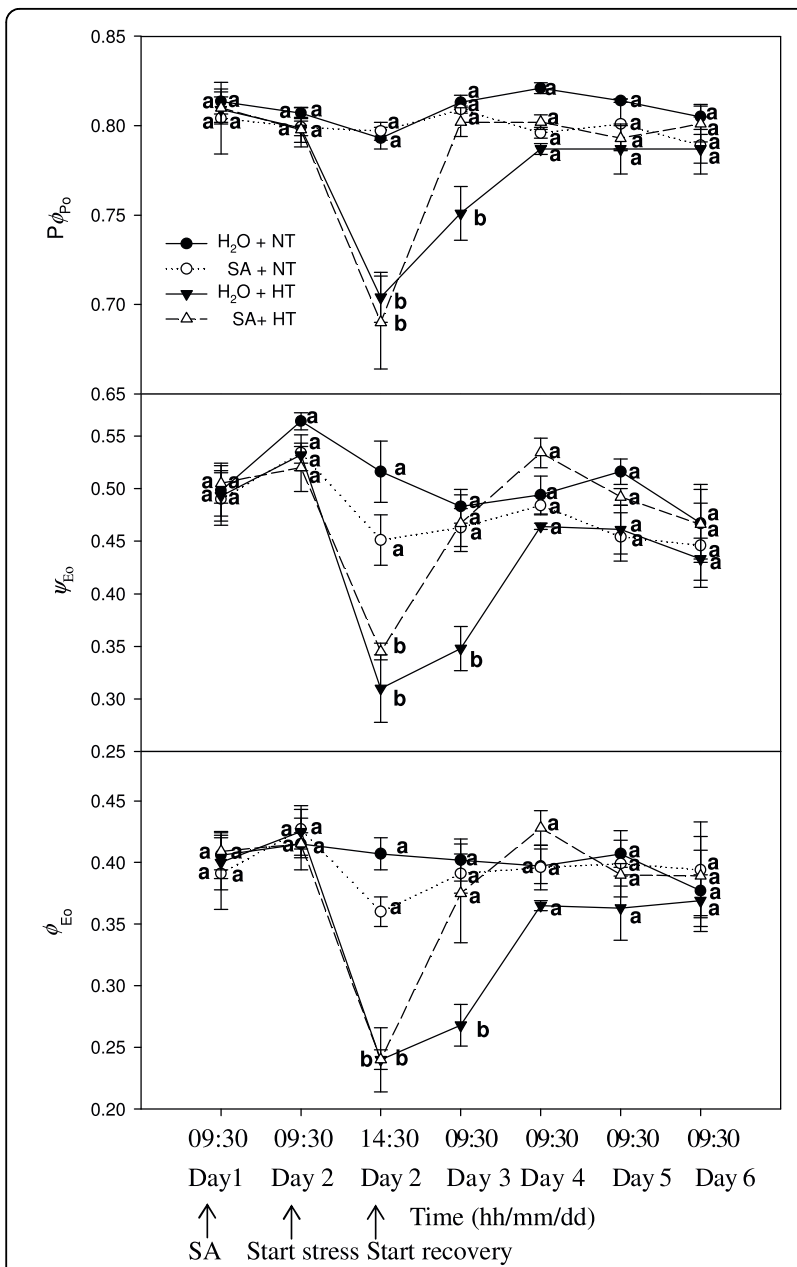

Figure $3 \varphi_{\mathrm{Po}}$ and acceptor parameters ( $\psi_{\mathrm{Eo}}$ and $\Phi_{\mathrm{Eo}}$ ) in leaves of grape plants sprayed with $\mathrm{H}_{2} \mathrm{O}$ (filled circles) and $\mathrm{SA}$ (open circles) at normal growth temperature $\left(\mathrm{NT}, 25^{\circ} \mathrm{C}\right)$, and treated with $\mathrm{H}_{2} \mathrm{O}$ (filled triangles) and $\mathrm{SA}$ (open triangles) under heat stress $\left(\mathrm{HT}, 43^{\circ} \mathrm{C}\right)$ and recovery. Each value is the mean $\pm \mathrm{SE}$ of 4 replicates. Treatment conditions are described in Fig. 1. At the same time point, numerical values with different letters are significantly different $(P<0.05)$.

techniques. Fig. 5 shows that SA had no effect on the actual PSII efficiency $\left(\Phi_{\text {PSII }}\right)$, the efficiency of excitation energy capture by open PSII reaction centers $\left(F_{\mathrm{v}}{ }^{\prime} / F_{\mathrm{m}}{ }^{\prime}\right)$, the photochemical quenching coefficient $\left(q_{\mathrm{p}}\right)$, or on non-photochemical quenching (NPQ) at the normal temperature. Heat stress led to a sharp decrease of $F_{\mathrm{v}}{ }^{\prime} /$ $F_{\mathrm{m}}{ }^{\prime}, \Phi_{\mathrm{PSII}}$ and $q_{\mathrm{p}}$, and a striking increase of NPQ irrespective of SA-treatment. With recovery, $F_{\mathrm{v}}{ }^{\prime} / F_{\mathrm{m}}{ }^{\prime}, \Phi_{\mathrm{PSII}}$ and $q_{\mathrm{p}}$ gradually rose; moreover, these parameters in SA-treated leaves were always greater than those in control leaves. $\Phi_{\mathrm{PSII}}$ values in SA-treated leaves were always significantly greater than in the control during recovery. On the first day of recovery (Day 3), NPQ of SA treatments declined rapidly, but NPQ of the controls remained higher. During the rest of the recovery period,

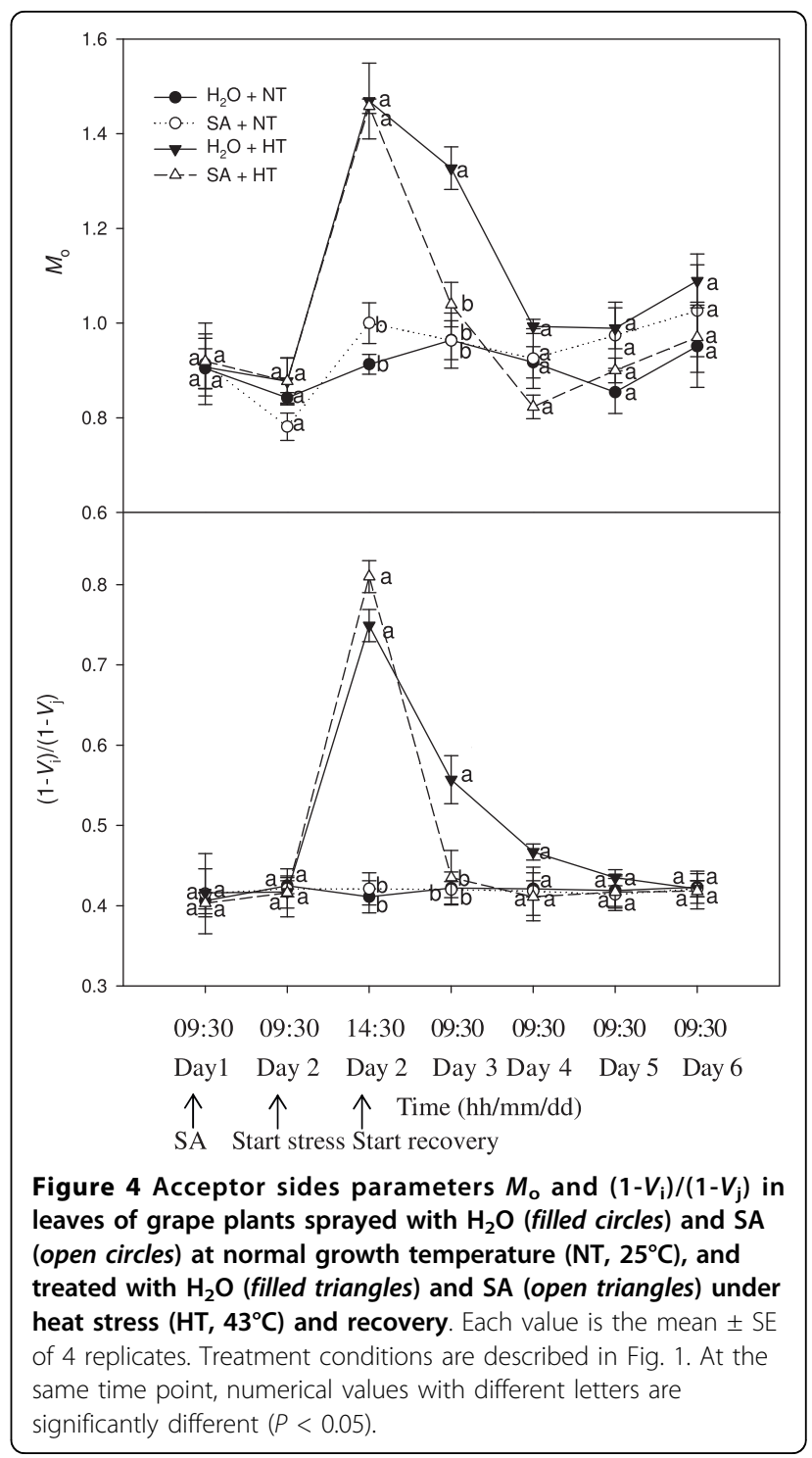

there were no obvious differences in NPQ between SA treatments and the controls.

\section{Rubisco activation state}

Fig. 6 demonstrates the changes in activation state of Rubisco (initial activities/total activities) in grape leaves. At normal temperatures, spraying SA did not change the ratio. In response to the heat stress, the ratio declined rapidly; however, SA-treated plants had a greater Rubisco activation state than the controls. During the recovery period, the Rubisco activation state of SA-treated leaves became similar to that of the non-stressed controls.

\section{HSP 21 in the chloroplast}

HSP21 is found only in the chloroplast, and a $21 \mathrm{kDa}$ peptide was in the grape leaves (Fig.7) in both SA-pretreated and control leaves. SA did not significantly $(P<0.05)$ 


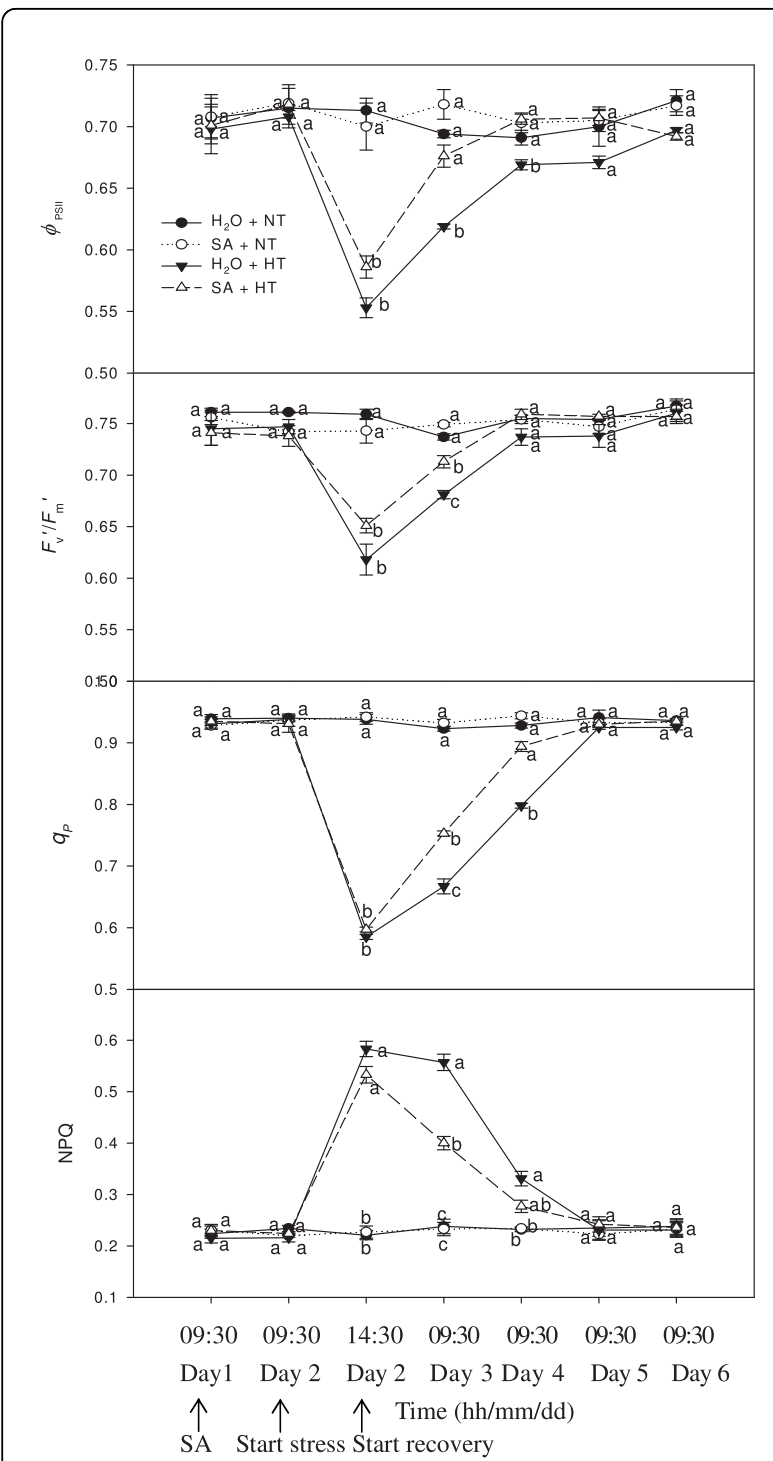

Figure 5 PSII efficiency and excitation energy dissipation in leaves of grape plants sprayed with $\mathrm{H}_{2} \mathrm{O}$ (filled circles) and SA (open circles) at normal growth temperature (NT, $25^{\circ} \mathrm{C}$ ), and treated with $\mathrm{H}_{2} \mathrm{O}$ (filled triangles) and $\mathrm{SA}$ (open triangles) under heat stress $\left(\mathbf{H T}, \mathbf{4 3}^{\circ} \mathrm{C}\right)$ and recovery. Each value is the mean $\pm \mathrm{SE}$ of 4 replicates. Treatment conditions are described in Fig. 1. At the same time point, numerical values with different letters are significantly different $(P<0.05)$.

change the immune signal of HSP21 before heat stress. When SA-pretreated and control leaves were stressed, they both showed higher levels of the immune signal. However, during recovery, HSP21 levels in the SA-pretreatment remained high until the end of the experiment while those in the control decreased below pre-stress levels.

\section{Discussion}

In this experiment, the $P_{\mathrm{n}}$ of plants sprayed with $\mathrm{H}_{2} \mathrm{O}$ and maintained at normal temperatures was $6.48 \pm 0.33$

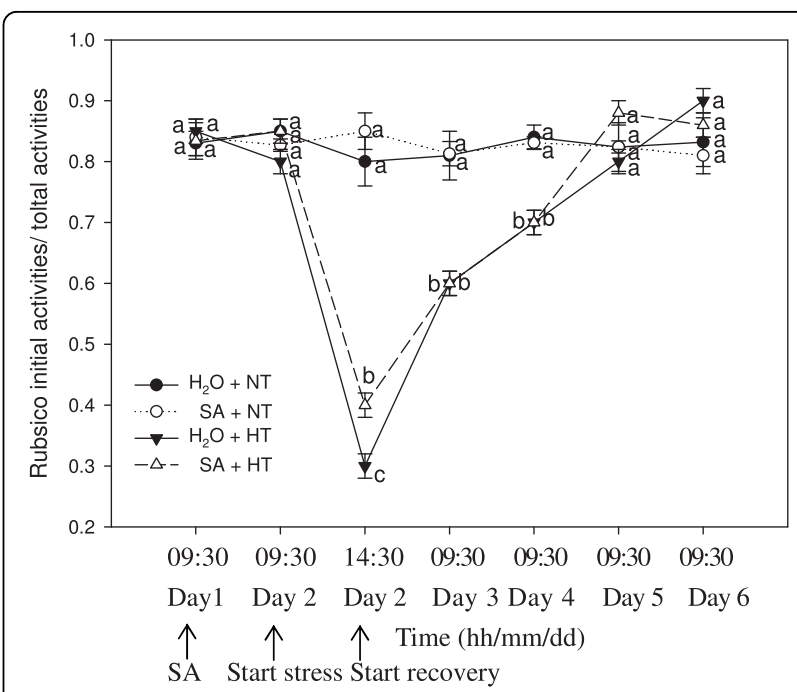

Figure 6 Rubisco activation state in leaves of grape plants sprayed with $\mathrm{H}_{2} \mathrm{O}$ (filled circles) and $\mathrm{SA}$ (open circles) at normal growth temperature (NT, $25^{\circ} \mathrm{C}$ ), and treated with $\mathrm{H}_{2} \mathrm{O}$ (filled triangles) and $\mathrm{SA}$ (open triangles) under heat stress $\left(\mathrm{HT}, 43^{\circ} \mathrm{C}\right)$ and recovery. Each value is the mean \pm SE of 4 replicates. Treatment conditions are described in Fig. 1. At the same time point, numerical values with different letters are significantly different $(P<0.05)$.

$\mu \mathrm{mol} \mathrm{m} \mathrm{s}^{-2}$ at 14:30 h on Day 2 of the experiment, significantly $(P<0.05)$ higher than the $P_{\mathrm{n}}$ of heat stressed plants sprayed with $\mathrm{H}_{2} \mathrm{O}$ or SA (Fig. 1). Therefore, the decrease of $P_{\mathrm{n}}$ of SA-treated and control leaves under heat stress from 9:30 to 14:30 h on Day 2 was not due to a diurnal change in photosynthesis, but instead due to heat stress. SA did not alter $P_{\mathrm{n}}$ significantly in plants maintained at the normal growth temperature, but it mitigated the decrease in $P_{\mathrm{n}}$ under heat stress and promoted the increase in $P_{\mathrm{n}}$ during recovery (Fig. 1). Under heat stress, change of $C_{\mathrm{i}}$ was opposite to that of $P_{\mathrm{n}}$ in the control and SA-treated leaves (Fig. 1), indicating that the decrease of $P_{\mathrm{n}}$ under heat stress was due to non-stomatal factors. During recovery, the strong decrease in $C_{\mathrm{i}}$ in control heat stressed plants (on Day 3) can be caused by the heat induced closing of stomata (less $g_{\mathrm{s}}$ ). Therefore, $g_{\mathrm{s}}$ may have been a main constraint to $P_{\mathrm{n}}$ for control plants at this time. But during the following recovery period, relative lower $P_{\mathrm{n}}$ for control plants was not accompanied by lower $C_{\mathrm{i}}$ and $g_{\mathrm{s}}$. SA treated leaves showed bigger $P_{\mathrm{n}}, C_{\mathrm{i}}$ and $g_{\mathrm{s}}$ after the first recovery day (Fig.1). These results may be related to electron transport and energy distribution. This can be seen by the changes in PSII parameters (Figs. 2, 3, 4 \&5).

PSII is often considered the most heat-sensitive component of the photochemistry, and the oxygen-evolving complex within the PSII is very sensitive to heat stress [33]. Obviously, an increase in heat resistance of the oxygen-evolving complex would help increase the 

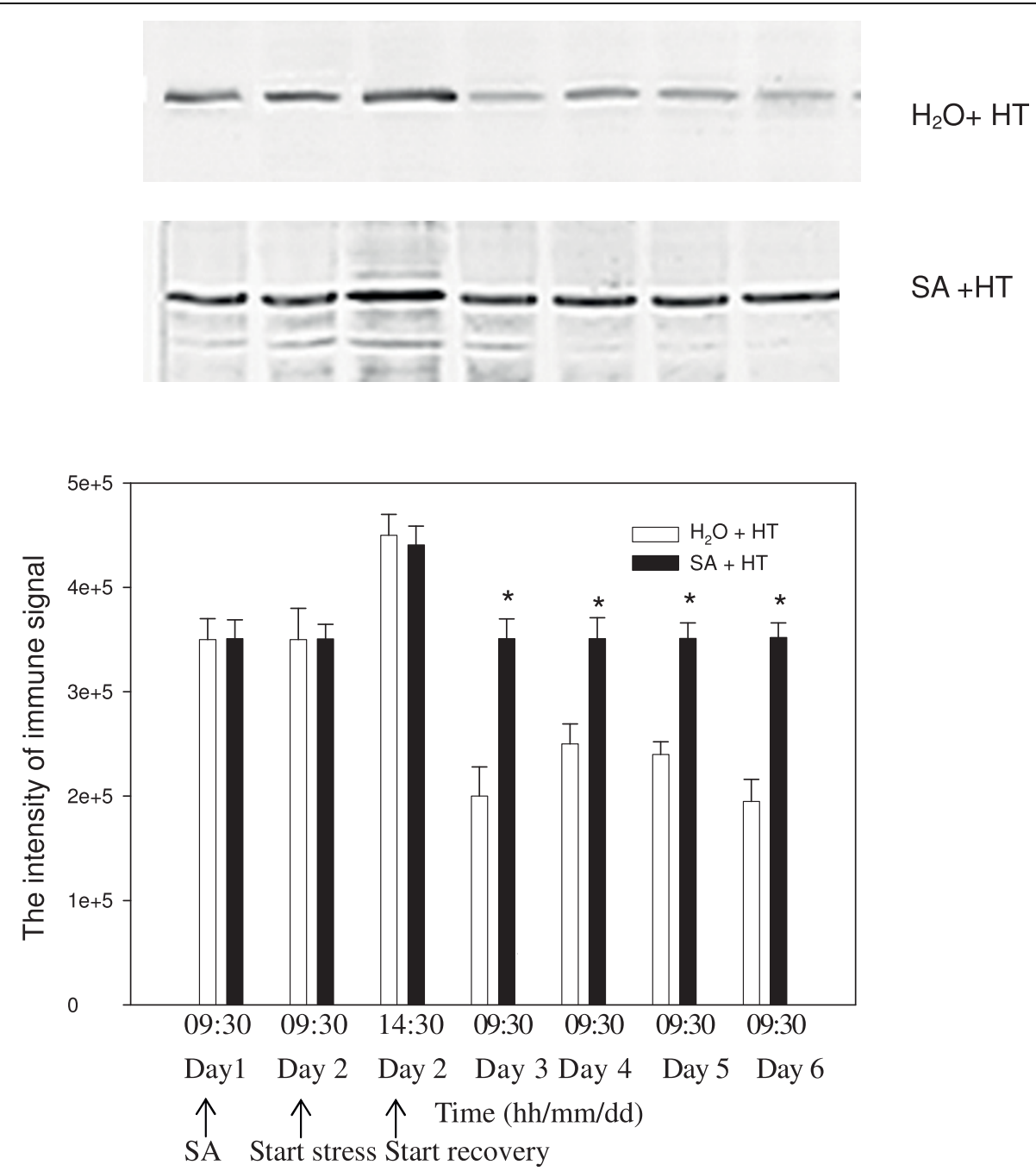

Figure 7 HSP21 in leaves of grape plants sprayed by treated with $\mathrm{H}_{2} \mathrm{O}$ and SA under heat stress $\left(\mathrm{HT}, 43^{\circ} \mathrm{C}\right)$ and recovery. Thylakoid membranes were extracted from leaves. Equal amounts $(10 \mu \mathrm{g})$ of protein were subjected to SDS-PAGE and transferred to a nitrocellulose membrane. Thereafter, the membrane was incubated with anti-Arabidopsis thaliana HSP21 antibody. Treatment conditions are described in Fig. 1. ${ }^{*}$ indicates a significant difference $(P<0.05)$ between the control and SA-treated plants at the same time point.

thermotolerance of PSII. Chlorophyll fluorescence parameters have been used to detect and quantify heat stress induced changes in PSII [34], and appearance of a K-step in the OJIP polyphasic fluorescence transient can be used as a specific indicator of injury to the oxygen-evolving complex [32]. In this study, we took advantage of the appearance of a K-step in the OJIP polyphasic fluoroscence transient to examine if SA-induced protection or improvement to PSII during heat stress and the recovery was related to the oxygen-evolving complex. $\mathrm{W}_{\mathrm{K}}$ in both control and SA treatments significantly increased when these plants were exposed to heat stress, but $\mathrm{W}_{\mathrm{K}}$ in the SA- treated plants dropped quickly while $\mathrm{W}_{\mathrm{K}}$ of the controls dropped slowly during recovery (Fig. 2). Therefore, the above hypothesis is supported by the data.
The PSII reaction center is also one of the sites damaged by heat stress [35]. Our results showed that the increased thermostability of PSII induced by SA treatment was partly associated with an increase in the thermostability of the PSII center. It was also observed that the density of $\mathrm{Q}_{\mathrm{A}}{ }^{-}$reducing PSII reaction centers in SA-treated plants increased more rapidly than in the controls during recovery from heat stress (Fig. 3). This was also confirmed by a quicker increase in SA-treated plants in $q_{\mathrm{p}}$ (Fig.5) which can represent the fraction of open PSII reaction centers [36]. The results support the hypothesis that SA-induced protection of PSII during heat stress and the recovery was involved in several aspects of PSII function, such as the $\mathrm{O}_{2}$-evolving complex and the PSII reaction center. 
In these experiments, the much lower $\psi_{\text {Eo }}$ and $\varphi_{\text {Eo }}$ showed that the activity of the electron transport beyond $\mathrm{Q}_{\mathrm{A}}$ was inhibited in heat stressed grape leaves (Fig. 2). The results indicated that heat stress also damaged the acceptor side of PSII. In addition, $\psi_{\text {Eo }}$ and $\varphi_{\text {Eo }}$ of SA-treated leaves increased more rapidly than that of the control leaves during recovery, indicating that SA can protect the acceptor side of PSII. In addition, the change in the ratio of $\left(1-V_{\mathrm{i}}\right) /\left(1-V_{\mathrm{j}}\right)$ may suggest that SA also protected PSI, allowing more rapid recovery from heat stress (Fig.5).

Efficiency of PSII under steady-state irradiance $\left(\Phi_{\mathrm{PSII}}\right)$ is the product of $q_{\mathrm{p}}$ and the efficiency of excitation capture $F_{\mathrm{v}}{ }^{\prime} / F_{\mathrm{m}}$ ' by open PSII reaction centers under nonphotorespiratory conditions. Under heat stress, SA-treated and control leaves had much lower $\Phi_{\text {PSII }}$ (Fig. 5), and had greater thermal dissipation of excitation energy as measured by increased NPQ (Fig. 5). With the recovery from heat stress, $\Phi_{\text {PSII }}$ of SA-treated and control plants gradually increased, and this was accompanied by increases in $F_{\mathrm{v}}{ }^{\prime} / F_{\mathrm{m}}$ ' and $q_{\mathrm{p}}$, and a rapid decline of NPQ in SA-treatment. However, NPQ of control plants slowly declined. In addition, $P_{\mathrm{n}}$ of SA-treated plants was greater than that of the control plants. This indicated that during recovery SA-treated plants do not need to dissipate much energy as heat, but instead are able to convert more energy into electron transport.

Inhibition of photosynthesis by heat stress has long been attributed to an impairment of electron transport [37]. However, other studies support the idea that the initial site of inhibition is associated with a Calvin cycle reaction, specifically the inactivation of Rubisco [38]. Measurements of the activation state of Rubisco in leaves, determined from the ratio of initial extractable activity to the activity after incubation under conditions that fully carbamylate the enzyme, show that the activation state of Rubisco decreases when net photosynthesis is inhibited by heat stress [39]. Here, under heat stress Ribisco activation state was greater in SA treated leaves than in the controls (Fig. 6), indicating that SA may alleviate Rubisco inactiviation under heat stress. However, SA treatment did nothing to improve the rate of recovery of the Rubisco activation state.

Evidence suggests that the small chloroplast heatshock protein (HSP21) is involved in plant thermotolerance, and protects the thermolabile PS II and wholechain electron transport $[12,40]$. HSPs including HSP21 have a high capacity to bind, stabilize and prevent protein aggregation, and help them regain normal function following stress [41]. In this study, HSP 21 levels increased in both SA-treated and control leaves during heat stress (Fig.7). Under severe heat stress, many proteins in the chloroplast are subject to denaturation, and HSPs function as molecular chaperones to provide protection. When stressed plants recover, HSPs are no longer made, and further degraded [42]; but, here in controls the levels of HSP21 decreased during the recovery to below initial levels (Fig.7). Similarly, Park et al [43] also reported that HSP18 levels in creeping bentgrass during recovery were lower than initially. However, SA treatment here maintained HSP21 at high levels in the recovery period. These data indicate that SA may alleviate Rubisco deactivation as well as enhance PSII recovery through HSP21.

\section{Conclusions}

SA pretreatment did not significantly influence photosynthesis of grape leaves at normal growth temperatures. However, SA pretreatment alleviated the decrease of $P_{n}$ under heat stress, apparently in part through maintaining a higher Rubisco activation state and greater PSII efficiency. SA also accelerated the increase of $P_{n}$ mainly through the more rapid recovery of PSII function after heat stress. These SA effects may be related to higher levels of HSP21. Other mechanisms by which SA protects photosynthesis in grape leaves are still to be determined.

\section{Methods}

\section{Plant materials and treatments}

Stem cuttings of grape (Vitis vinifera L.) 'Jingxiu' were rooted in the pots containing a mixture of 4 peatmoss: 6 perlite $(\mathrm{V} / \mathrm{V})$ and grown in a greenhouse under mist conditions. When the cuttings were rooted, they were repotted into larger pots, grown for about 10 weeks in a greenhouse at $70-80 \%$ relative humidity, $25 / 18^{\circ} \mathrm{C}$ day/ night cycle, and with the maximum photosynthetically active radiation at about $1,000 \mu \mathrm{mol} \mathrm{m} \mathrm{m}^{-2} \mathrm{~s}^{-1}$.

Young grape plants with identical growth (10 leaves) were acclimated for two days in a controlled environment room $\left(70-80 \%\right.$ relative humidity, $25 / 18^{\circ} \mathrm{C}$ day/ night cycle and $800 \mu \mathrm{mol} \mathrm{m} \mathrm{m}^{-2} \mathrm{~s}^{-1}$ ) and divided into two groups. On the following day (the first day of the experiment, Day 1), chlorophyll fluorescence and gas exchange parameters were analyzed at 9:30 h for all plants. One group of plants was then sprayed with $100 \mu \mathrm{M}$ SA solution, and the other group was sprayed with water. On Day 2, the same parameters were measured at 9:30 h. Half of the SA-treated and $\mathrm{H}_{2} \mathrm{O}$-treated plants were then heat stressed at $43^{\circ} \mathrm{C}$ until $14: 30 \mathrm{~h}$; the other half remained at $25^{\circ} \mathrm{C}$ until 14:30 h. Relative photosynthesis parameters were then rapidly measured. The stressed plants were then allowed to recover at $25^{\circ} \mathrm{C}$. Chlorophyll florescence and gas exchange parameters were measured at 9:30 h each day during the following four days of recovery (Day 3, Day 4, Day 5 and Day 6). All of the above measurements were made on the fifth leaf from the top of each plant. Four replications were made with leaves from different grape plants. 


\section{Analysis of photosynthetic gas exchange}

Photosynthetic gas exchange was analyzed with a Li-Cor 6400 portable photosynthesis system which can control photosynthesis by means of photosynthetic photon flux density (PPFD), leaf temperature and $\mathrm{CO}_{2}$ co-ncentration in the cuvette. Net photosynthetic rate $\left(P_{\mathrm{n}}\right)$, stomatal conductance $\left(g_{\mathrm{s}}\right)$ and substomatal $\mathrm{CO}_{2}$ concentration $\left(C_{\mathrm{i}}\right)$ were determined at a concentration of ambient $\mathrm{CO}_{2}$ $\left(360 \mu \mathrm{mol} \mathrm{mol}^{-1}\right)$ and a PPFD of $800 \mu \mathrm{mol} \mathrm{m}^{-2} \mathrm{~s}^{-1}$.

\section{Analysis of chlorophyll fluorescence}

Chlorophyll fluorescence was measured with a FM-2 Pulse-modulated Fluorimeter (Hansatech, UK). The maximal fluorescence level in the dark-adapted state $\left(F_{\mathrm{m}}\right)$ were measured by a $0.8 \mathrm{~s}$ saturating pulse at 8000 $\mu \mathrm{mol} \mathrm{m} \mathrm{m}^{-2} \mathrm{~s}^{-1}$ after $20 \mathrm{~min}$ of dark adaptation. When measuring the induction, the actinic light was offered by the FMS-2 light source. The steady-state fluorescence $\left(F_{\mathrm{s}}\right)$ was thereafter recorded and a second $0.8 \mathrm{~s}$ saturating light of $8000 \mu \mathrm{mol} \mathrm{m} \mathrm{m}^{-2}$ was given to determine the maximum fluorescence in the light-adapted state $\left(F_{\mathrm{m}}{ }^{\prime}\right)$. The actinic light was then turned off; the minimal fluorescence in the light-adapted state $\left(F_{\mathrm{o}}{ }^{\prime}\right)$ was determined by illumination with $3 \mathrm{~s}$ of far red light. The following parameters were then calculated: (1) efficiency of excitation energy captured by open PSII reaction centers, $F_{\mathrm{v}}{ }^{\prime} / F_{\mathrm{m}}{ }^{\prime}=\left(F_{\mathrm{m}}{ }^{\prime}-F_{\mathrm{o}}{ }^{\prime}\right) / F_{\mathrm{m}}{ }^{\prime} ;(2)$ the photochemical quenching coefficient, $q_{\mathrm{p}}=\left(F_{\mathrm{m}}{ }^{\prime}-F_{\mathrm{s}}\right) /\left(F_{\mathrm{m}}{ }^{\prime}-F_{\mathrm{o}}{ }^{\prime}\right)$; (3) the actual PSII efficiency, $\Phi_{\mathrm{PSII}}=\left(F_{\mathrm{m}}{ }^{\prime}-F_{\mathrm{s}}\right) / F_{\mathrm{m}}{ }^{\prime} ;$ and $(4)$ non-photochemical quenching, $\mathrm{NPQ}=F_{\mathrm{m}} / F_{\mathrm{m}}{ }^{\prime}-1[44]$.

\section{Measurement of the polyphasic transient of chlorophyll a fluorescence (OJIP test)}

The so-called OJIP-test was employed to analyze each chlorophyll a fluorescence transient by a Handy Plant Efficiency Analyzer (PEA, Hansatech, UK), which could provide information on photochemical activity of PSII and status of the plastoquinone pool [45]. Before measurement, leaves were dark-acclimated for 20 minutes. The transients were induced by red light of about 3000 $\mu \mathrm{mol}$ photons $\mathrm{m}^{-2} \mathrm{~s}^{-1}$ provided by an array of six light emitting diodes (peak $650 \mathrm{~nm}$ ). The fluorescence signals were recorded within a time span from $10 \mu \mathrm{s}$ to $1 \mathrm{~s}$ with a data acquisition rate of $10 \mu \mathrm{s}$ for the first $2 \mathrm{~ms}$ and every $1 \mathrm{~ms}$ thereafter. The fluorescence signal at 50 $\mu$ s was considered as a true $F_{\mathrm{o}}$. The following data from the original measurements were used: maximal fluorescence intensity $\left(F_{\mathrm{m}}\right)$; fluorescence intensity at $300 \mu \mathrm{s}$ $\left(F_{\mathrm{k}}\right)$ [required for calculation of the initial slope $\left(M_{\mathrm{o}}\right)$ of the relative variable fluorescence $(\mathrm{V})$ kinetics and $W_{\mathrm{k}}$ ]; and the fluorescence intensity at $2 \mathrm{~ms}$ (the J-step) denoted as $F_{\mathrm{j}}$, the fluorescence intensity at $30 \mathrm{~ms}$ (the Istep) denoted as $F_{\mathrm{i}}$. Terms and formulae are as follows: a parameter which represent the damage to oxygen evolving complex (OEC), $\left.W_{\mathrm{k}}=\left(F_{\mathrm{k}}-F_{\mathrm{o}}\right) / F_{\mathrm{j}}-F_{\mathrm{o}}\right)$; approximated initial slope of the fluorescence transient, $M_{\mathrm{o}}=4\left(F_{\mathrm{k}}-F_{\mathrm{o}}\right) /\left(F_{\mathrm{m}}-F_{\mathrm{o}}\right) ;$ probability that a trapped exciton moves an electron into the electron transport chain beyond $\mathrm{Q}_{\mathrm{A}}{ }^{-}, \psi_{\text {Eo }}=E T_{\mathrm{o}} / \mathrm{TR}_{\mathrm{o}}=\left(F_{\mathrm{m}}-F_{\mathrm{j}}\right) /\left(F_{\mathrm{m}}-F_{\mathrm{o}}\right)$; quantum yield for electron transport (at $\mathrm{t}=0), \Phi_{\mathrm{Eo}}=$ $E T_{\mathrm{o}} / \mathrm{ABS}=\left[1-\left(F_{\mathrm{o}} / F_{\mathrm{m}}\right)\right] \times \psi_{\mathrm{Eo}}$; and the density of $\mathrm{Q}_{\mathrm{A}^{-}}$ reducing reaction centers, $\mathrm{RC}_{\mathrm{QA}}=\varphi_{\mathrm{Po}} \times\left(\mathrm{V}_{\mathrm{j}} / M_{\mathrm{o}}\right) \times$ (ABS/CS). The formulae in Table 1 illustrate how each of the above-mentioned biophysical parameters can be calculated from the original fluorescence measurements.

\section{Table 1 Summary of parameters, formulae and their description using data extracted from chlorophyll a fluorescence (OJIP) transient.}

\begin{tabular}{ll}
\hline Fluorescence parameters & Description \\
\hline$F_{\mathrm{t}}$ & $\begin{array}{l}\text { Fluorescence intensity at time t after } \\
\text { onset of actinic illumination }\end{array}$ \\
$F_{50 \mu \mathrm{s}}$ & Minimum reliable recorded fluorescence \\
& at $50 \mu \mathrm{s}$ with the PEA fluorimeter \\
$F_{\mathrm{k}}\left(\mathrm{F}_{300 \mu \mathrm{s}}\right)$ & Fluorescence intensity at $300 \mu \mathrm{s}$ \\
$F_{\mathrm{P}}$ & Maximum recorded (= maximum \\
& possible) fluorescence at P-step \\
Area & Total complementary area between \\
& fluorescence induction curve and \\
ABS & F = Fm \\
TR & Absorption of energy \\
CS & Trap of energy \\
Excited Cross section
\end{tabular}

Derived parameters (Selected OJIP parameters)

$F_{0} \cong F_{50 \mu s} \quad$ Minimum fluorescence, when all PSII RCs

$\begin{array}{ll}F_{\mathrm{m}}=F_{\mathrm{P}} & \text { Maximum fluoresc } \\ & \mathrm{RCs} \text { are closed }\end{array}$ are open

$V_{\mathrm{j}}=\left(F_{2 \mathrm{~ms}}-F_{\mathrm{o}}\right) /\left(F_{\mathrm{m}}-F_{\mathrm{o}}\right) \quad$ Relative variable fluorescence at the J-step (2 ms)

$V_{\mathrm{i}}=\left(F_{30 \mathrm{~ms}}-F_{\mathrm{o}}\right) /\left(F_{\mathrm{m}}-F_{\mathrm{o}}\right) \quad$ Relative variable fluorescence at the I-step (30 ms)

$W_{K}=\left(F_{300 \mu s}-F_{0} /\left(F_{j}-F_{0}\right) \quad\right.$ Represent the damage to oxygen evolving complex OEC

$M_{\mathrm{o}}=4\left(F_{300 \mu \mathrm{s}}-F_{\mathrm{o}}\right) /\left(F_{\mathrm{m}}-F_{\mathrm{o}}\right) \quad$ Approximated initial slope of the fluorescence transient

Yields or flux ratios

$\varphi_{\mathrm{PO}_{\mathrm{O}}}=\mathrm{TR} / \mathrm{ABS}=1-\left(F_{\mathrm{o}} / F_{\mathrm{m}}\right)$ $=F_{\mathrm{v}} / F_{\mathrm{m}}$

$\varphi_{\mathrm{EO}_{\mathrm{O}}}=\mathrm{ET}_{\mathrm{o}} / \mathrm{ABS}=\left(F_{\mathrm{v}} / F_{\mathrm{m}}\right) \times$

$\left(1-V_{j}\right)$

$\psi_{\mathrm{Eo}}=\mathrm{ET}_{\mathrm{o}} / \mathrm{TR}_{\mathrm{o}}=1-V_{\mathrm{j}}$

Maximum quantum yield of primary photochemistry at $\mathrm{t}=0$

Quantum yield for electron transport at $\mathrm{t}=0$

Probability (at time 0) that a trapped exciton moves an electron into the electron transport chain beyond $\mathrm{Q}_{\mathrm{A}}{ }^{-}$

$\delta_{\mathrm{Ro}}=\left(1-V_{\mathrm{i}}\right) /\left(1-V_{\mathrm{j}}\right)$

Efficiency with which an electron can move from the reduced intersystem, electron acceptors to the PSI end electron acceptors

Density of reaction centers. Amount of active PSII RCS (QA-reducing $\mathrm{RC}_{\mathrm{QA}}=\varphi_{\mathrm{PO}_{\mathrm{O}}} \times\left(\mathrm{ABS} / \mathrm{CS}_{\mathrm{m}}\right) \times \quad \mathrm{PSIl}$ reaction centers $)$ per $\mathrm{CS}$ at $\mathrm{t}=\mathrm{m}$ $\left(V_{\mathrm{j}} / M_{\mathrm{o}}\right)$ 


\section{Extraction and assay of Ribulose-1,5-bisphosphate carboxylase/oxygenase (Rubisco, EC4.1.1.39)}

Leaves disks $\left(1 \mathrm{~cm}^{2}\right.$ each) were taken, then frozen in liquid nitrogen, and stored at $-80^{\circ} \mathrm{C}$ until assay. Rubisco was extracted according to Chen and Cheng [46]. Three frozen leaf disks were ground with a pre-cooled mortar and pestle in $1.5 \mathrm{~mL}$ extraction buffer containing 50 $\mathrm{mM}$ Hepes-KOH (pH7.5), $10 \mathrm{mM} \mathrm{MgCl} 2,2 \mathrm{mM}$ EDTA, $10 \mathrm{mM}$ dithiothreitol (DDT), 1\% (v/v) Triton X-100, 1\% $(\mathrm{w} / \mathrm{v})$ bovine serum albumin (BSA), 10\% (v/v) glycerol, $0.5 \mathrm{mM}$ phenylmethylsulfonyl fluoride (PMSF), and 5\% $(\mathrm{w} / \mathrm{v})$ insoluble polyvinylpolypyrrolidone (PVPP). The extract was centrifuged at $13000 \times \mathrm{g}$ for $5 \mathrm{~min}$ in an Eppendorf microcentrifuge at $4^{\circ} \mathrm{C}$, and the supernatant was used immediately for enzyme assays.

For Rubisco initial activity, a $50 \mu \mathrm{l}$ sample extract was added to a semi-microcuvette containing $900 \mu \mathrm{l}$ of an assay solution, immediately followed by adding $50 \mu \mathrm{l} 0.5$ $\mathrm{mM}$ RuBP, mixing well. The change of absorbance at $340 \mathrm{~nm}$ was monitored for $40 \mathrm{~s}$. For Rubisco total activity, $50 \mu \mathrm{l} 0.5 \mathrm{mM}$ RuBP was added $15 \mathrm{~min}$ after a sample extract was combined with assay solution to activate all the Rubisco fully. Rubisco activation state was calculated as the ratio of initial activity to total activity $[46,47]$.

\section{Tissue fractionation and western blot analysis for heat shock proteins (HSP21)}

Total protein was extracted according to the methods of Hong et al. [48] with some modification. Leaves were immediately frozen in liquid nitrogen and homogenized 1:3 (w/v) in $150 \mathrm{mM}$ Tris buffer, $\mathrm{pH} 7.8$, containing $2 \mathrm{mM}$ EDTA- $\mathrm{Na}_{2}, 10 \mathrm{mM}$ ascorbic acid, $10 \mathrm{mM} \mathrm{MgCl}_{2}$, $1 \mathrm{mM}$ PMSF, 0.2\% (v/v) 2-mercaptoethanol, 2\% (w/v) PVPP and $2 \%(\mathrm{w} / \mathrm{v})$ SDS. Protein extracts were centrifuged at $12000 \times \mathrm{g}$ for $15 \mathrm{~min}$ and the procedure repeated twice.

For western blot analysis, SDS-PAGE was carried out in $10 \%(\mathrm{v} / \mathrm{v})$ acrylamide slab gels, the samples were diluted with an equal volume of buffer and heated at $100^{\circ} \mathrm{C}$ for $5 \mathrm{~min}$, then centrifuged at $10,000 \times \mathrm{g}$ for 10 min. Polypeptides were separated using Bio-Rad Miniprotean II slab cell. Electrophoretic transfer of polypeptides from SDS polyacrylamide gels to nitrocellulose membranes ( $0.45 \mathrm{~mm}$, Amersham Life Science) was conducted in $25 \mathrm{mM}$ Tris ( $\mathrm{pH} 8.3$ ), $192 \mathrm{mM}$ glycine and $20 \%(\mathrm{w} / \mathrm{v})$ methanol. After rinsing in TBS buffer $(10$ $\mathrm{mM}$ Tris- $\mathrm{HCl}, \mathrm{pH} 7.5,150 \mathrm{mM} \mathrm{NaCl}$ ), the membranes were preincubated for $2 \mathrm{~h}$ at room temperature in a blocking buffer containing $1 \%(\mathrm{w} / \mathrm{v})$ bovine serum albumin (BSA) dissolved in TBST [TBS, 0.05\% (v/v) Tween 20]. They were then incubated with gentle shaking for 2 $\mathrm{h}$ at room temperature in Arabidopsis anti-HSP21 antibody (Agrisera Company, Sweden). Following extensive washes with TBST buffer, the membranes were incubated with goat antirabbit IgG-alkaline phosphatase conjugate (1:1000 diluted in TBST) at room temperature for $1 \mathrm{~h}$, and were then washed with TBST. The locations of antigenic proteins were visualized by incubating the membranes with 5-bromo-4-chloro-3-indolyl. Protein concentrations were determined by the method of Bradford [49] with BSA as a standard.

\section{Statistical analyses}

Data were processed with SPSS 13.0 for Windows, and each mean and standard error in the figures represents four replicate measurements. Differences were considered significant at a probability level of $P<0.05$.

\section{Abbreviations}

$C_{\text {: }}$ : substomatal $\mathrm{CO}_{2}$ concentration; $F_{0}^{\prime}$ and $F_{m}^{\prime}$ : the minimal and maximum fluorescence in the light-adapted state; $F_{\mathrm{s}}$ : the steady-state fluorescence; $F_{\mathrm{v}}{ }^{\prime}$ l $F_{\mathrm{m}}$ ': efficiency of excitation energy capture by open PSII reaction centers; HSP: heat shock protein; NPQ: non-photochemical quenching; OEC: oxygen evolving complex; $P_{n}$ : net photosynthetic rate; PSII: photosystem II; $\mathrm{RC}_{\mathrm{QA}}$ : density of QA -reducing reaction centers; Rubisco: ribulose bisphosphate carboxylase/oxygenase; $q_{\mathrm{p}}$ : photochemical quenching coefficient; RuBP: ribulose-1,5- bisphosphate; SA: salicylic acid; $\Phi_{P S I I}$ : actual PSII efficiency; $M_{0}$ : approximated initial slope of the fluorescence transient; $\psi_{\text {EO }}$ : probability that a trapped exciton moves an electron into the electron transport chain beyond $\mathrm{QA}^{-} ; \varphi_{\mathrm{EO}}$ : quantum yield for electron transport.

\section{Acknowledgements}

This work was supported in part by National Natural Science Foundation of China (No.30771758). We thank Professor Huiyuan Gao in Shandong Agricultural University, Drs Shouren Zhang and Benhong Wu in the Institute of Botany, Chinese Academy of Sciences for their advice.

\section{Author details}

${ }^{1}$ Institute of Botany, Chinese Academy of Sciences, Beijing, 100093, PR China. ${ }^{2}$ College of Agriculture and Biology Technology, China Agricultural University, Beijing 100093, PR China. ${ }^{3}$ College of Agriculture and Natural Resources, Michigan State University, East Lansing, 48824, MI, USA. ${ }^{4}$ Key Laboratory of Pant Germplasm Enhancement and Speciality Agriculture, Wuhan Botanical Garden, Chinese Academy of Sciences, Wuhan 430074, PR China.

\section{Authors' contributions}

$W L J$ designed the experiments, performed a part of the experiments and wrote the manuscript. FL performed a part of the experiments. LW helped design the experiment and reviewed the manuscript. DW helped design the experiment. LGJ helped design the experiment. CJS and LHB helped in measuring $\mathrm{CO}_{2}$ assimilation and chlorophyll a fluorescence. LSH directed the study. All authors have read and approved the final manuscript.

Received: 13 July 2009 Accepted: 23 February 2010

Published: 23 February 2010

\section{References}

1. Lobell DB, Asner GP: Climate and management contributions to recent trends in U.S. agricultural yields. Science 2003, 299:1032.

2. Weis E, Berry JA: Plants and high temperature stress. Symp Soc Exp Biol 1988, 42:329-346.

3. Wise RR, Olson AJ, Schrader SM, Sharkey TD: Electron transport is the functional limitation of photosynthesis in field-grown Pima cotton plants at high temperature. Plant Cell Environ 2004, 25:717-724.

4. Ronde JADD, Cress WA, Kruger GHJ, Strasser RJ, Staden JV: Photosynthetic response of transgenic soybean plants containing an Arabidopsis P5CR gene, during heat and drought stress. J Plant Physiol 2004, 61:1211-1244. 
5. De las Rivas J, Barber J: Structure and thermal stability of photosystem II reaction centers studied by infrared spectroscopy. Biochem 1997, 36:8897-8903.

6. Pospýsil P, Tyystjarvi E: Molecular mechanism of high-temperature induced inhibition of acceptor side of photosystem II. Photosynth Res 1999, 62:55-66

7. Bukhoc NG, Carpentier R: Heterogeneity of photosystem II reaction centers as influenced by heat treatment of barley leaves. Physiol Plant 2000, 110:259-285.

8. Wen $X G$, Gong HM, Lu CM: Heat stress induces a reversible inhibition of electron transport at the acceptor side of photosystem II in a cyanobacterium Spirulina platensis . Plant Sci 2005, 168:1471-1476.

9. Delfine $S$, Alvino A, Zacchini M, Loreto F: Consequences of salt stress on $\mathrm{CO}_{2}$ diffusion, Rubisco characteristics and anatomy of spinach leaves. Aust J Plant Physiol 1998, 25:395-402.

10. Havaux M, Tardy F, Ravenal J, Chanu D, Parot P: Thylakoid membrane stability to heat stress studied by flash spectroscopic measurements of the electrochromic shift in intact potato leaves: influence of the xanthophyll content. Plant Cell Environ 1996, 9:1359-1368.

11. Tardy F, Havaux M: Thylakoid membrane fluidity and thermostability during the operation of the xanthophyll cycle in higher-plant chloroplasts. Biochem Biophys Acta 1997, 330:179-193.

12. Heckathorn SACA, Downs TD, Sharkey JS, Coleman G: The small, methionine-rich chloroplast heat-shock protein protects photosystem II electron transport during heat stress. Plant Physiol 1998, 116:439-444.

13. Zhang $X Z$, Ervin EH, Schmidt RE: Plant growth regulators can enhance the recovery of Kentucky bluegrass sod from heat injury. Crop Sci 2003 43:952-956.

14. Horvath E, Szalai G, Janda T: Induction of abiotic stress tolerance by salicyclic acid signaling. J Plant Growth Regul 2007, 26:290-300.

15. Raskin I: Role of salicylic acid in plants. Annu Rev Plant Physiol Plant Mol Biol 1992, 43:439-63.

16. Arfana M, Atharb HR, Ashraf M: Does exogenous application of salicylic acid through the rooting medium modulate growth and photosynthetic capacity in two differently adapted spring wheat cultivars under salt stress?. J Plant Physiol 2007, 164:685-694.

17. El-Tayeb MA: Response of barley grains to the interactive effect of salinity and salicylic acid. Plant Growth Regul 2005, 45:215-24.

18. Munne-Bosch S, Penuelas J: Photo- and antioxidantive protection, and a role for salicylic acid during drought and recovery in field-grown Phillyrea angustifolia plants. Planta 2003, 217:758-766.

19. Singh B, Usha K: Salicylic acid induced physiological and biochemical changes in wheat seedlings under water stress. Plant Growth Regul 2003, 39:137-141.

20. Dat JF, Lopez-Delgado $\mathrm{H}_{\text {, Foyer }} \mathrm{CH}_{1}$ Scott IM: Paralell changes in $\mathrm{H}_{2} \mathrm{O}_{2}$ and catalase during thermotolerance induced by salicylic acid or heat acclimation in mustard plants. Plant Physiol 1998, 116:1351-1357.

21. Dat JF, Foyer $\mathrm{CH}$, Scott IM: Change in salicylic acid and antioxidants during induced thermotolerance in mustard seedlings. Plant Physiol 1998, 118:1445-1456.

22. Lopez-Delgado H, Dat JF, Foyer $\mathrm{CH}$, Scott IM: Induction of thermotolerance in potato microplants by acetylsalicylic acid and $\mathrm{H}_{2} \mathrm{O}_{2}$. J Exp Bot 1998, 49:713-720.

23. Senaratna T, Touchell D, Bumm E, Dixon K: Acetylsalicylic (Aspirin) and salicylic acid induce multiple stress tolerance in bean and tomato plants. Plant Gowth Regul 2000, 30:157-61

24. Clark SM, Mur LAJ, Wood JE, Scott IM: Salicylic acid dependent signaling promotes basal thermotolerance but is not essential for acquired thermotolerance in Arabidopsis thaliana . Plant J 2004, 38:432-437.

25. Wang LJ, Li SH: Salicylic acid-induced heat or cold tolerance in relation to $\mathrm{Ca}^{2+}$ homeostasis and antioxidant systems in young grape plants. Plant Sci 2006, 170:685-694

26. Wang $L$, Li SH: The effects of salicylic acid on distribution of ${ }^{14} \mathrm{C}$ assimilation and photosynthesis in young grape plants under heat stress. Acta Horticulture 2007, 738:779-7851.

27. Domonkos P: Recent precipitation trends in Hungary in the context of larger scale climatic changes. Natural Hazards 2003, 29:255-271.

28. Van Leeuwen $C$, Friant $P$, Chone $X$, Tregoat $O$, Koundouras $S$,

Dubourdieu D: The influence of climate, soil and cultivar on terroir. Am J Enol Viticult 2004, 55:207-217.
29. Zsófi Z, Gál L, Szilágyi Z, Szucs E, Marschall M, Nagy Z, Bálo B: Use of stomatal conductance and pre-dawn water potential to classify terroir for the grape variety Kékfrankos. Aust J Grape Wine R 2009, 15:36-47.

30. Schultz HR: Climate change and world viticulture. Cost Action 858 Workshop: Vineyard under environmental constraints: adaptations to climate change. Abiotic stress ecophysiology and grape functional genomics. Poland: University of Lodz 2007.

31. Srivastava A, Guisse B, Greppin H, Strasser RJ: Regulation of antenna structure and electron transport in photosystem II of Pisum sativum under elevated temperature probed by the fast t polyphasic chlorophyll a fluorescence transient: OKJIP. Bio-chim Biophys Acta 1997, 95-106.

32. Strasser BJ: Donor side capacity of photosystem II probed by chlorophyll a fluorescence transients. Photosynth Res 1997, 52:147-155.

33. Lu CM, Zhang J: Heat -induced multiple effects on PSII in wheat plants. $J$ Plant Physiol 2000, 156:259-265

34. Berry J, Bjorkman O: Photosynthetic response and adaptation to temperature in higher plants. Annu Rev Plant Physiol 1980, 31:491-543.

35. Cao J, Govindjee : Chlorophyll $a$ fluorescence transients as an indicator of active and inactive photosystem II in thylakoid membranes. Biochim Biophys Acta 1990, 1015:180-188.

36. Kooten O, Snel JFH: The use of chlorophyll fluorescence nomenclature in plant stress physiology. Photosyn Res 1990, 25:147-150

37. Lu CM, Zhang JH: Photosystem II photochemistry and its sensitivity to heat stress in maize plants as affected by nitrogen deficiency. J Plant Physiol 2000, 157:124-130.

38. Salvucci ME, Crafts-Brandner SJ: Inhibition of photosynthesis by heat stress: the activation state of Rubisco as a limiting factor in photosynthesis. Physiol Plant 2004, 120:179-186.

39. Yamori W, Suzuki K, Noguchi K, Nakai M, Terashima I: Effect of Rubisco kinetics and Rubisco activation state on the temperature dependence of the photosynthetic rate in spinach leaves from contrasting growth temperatures. Plant Cell Environ 2006, 29:1659-1670.

40. Neta-Sharir I, Isaacson T, Lurie S, Weiss D: Dual role for tomato heat shock protein 21: protecting photosystem II from oxidative stress and promoting color changes during fruit maturation. Plant Cell 2005, 17:1829-1838.

41. Wang WX, Vinocur B, Shoseyov O, Altman A: Role of plant heat-shock proteins and molecular chaperones in the abiotic stress response. Trends in Plant Science 2004, 9:244-252.

42. Didomenico BJ, Bugaisky $G$, Lindquist $S$ : Heat shock and recovery are mediated by different translational mechanisms. Proc Natl Acad Sci USA 1982, 79:6181-6185.

43. Park SY, Chang KC, Shivaji R, Luthe DS: Recovery from heat shock in heattolerant and nontolerant variants of creeping bentgrass. Plant Physiol 1997, 115:229-240

44. Demmig-Adams B, Adams WW III, Barker DH, Logan BA, Bowling DR, Verhoeven AS: Using chlorophyll fluorescence to assess the fraction of absorbed light allocted to thermal dissipation of excess excitation. Physiol Plant 1986, 98:253-264.

45. Strauss AJ, Krüger GHJ, Strasser RJ, Van Heerden PDR: Ranking of dark chilling tolerance in soybean genotypes probed by the chlorophyll a fluorescence transient O-J-I-P. Environ Exp Bot 2006, 56:147-157.

46. Chen LS, Cheng LL: Carbon assimilation and carbohydrate metabolism of 'Concord' grape (Vitis labrusca L.) leaves in response to nitrogen supply. J Am Soc Hort Sci 2003, 128:754-760.

47. Cheng LL, Fuchigami LH: Rubisco activation state decreases with increasing nitrogen content in apple leaves. J Exp Bo 2000, 51:1687-1694.

48. Hong SW, Lee U, Vierling E: Arabidopsis hot multiple functions required for acclimation to high temperatures. Plant Physiol 2003, 132:757-767.

49. Bradford MM: A rapid and sensitive method for the quantitation of microgram quantities of protein utilizing the principle of protein-dye binding. Ana Biochem 1976, 72:248-254

doi:10.1186/1471-2229-10-34

Cite this article as: Wang et al: Salicylic acid alleviates decreases in photosynthesis under heat stress and accelerates recovery in grapevine leaves. BMC Plant Biology 2010 10:34. 